received from publishers, yet others offer short individual articles on a number. There is the big essay review and the series of short notices. How much precious space should be given up to books, and what is of most use to readers? Psychological Medicine allows about ten pages a time, and compromises with a book list, a few short essay reviews, and a number of snappy characteristic sharply critical brief notices which are entertaining but not always very useful. Crowds of books are published or re-issued each year; do we need a firm guide through the crush so that we can all track our special interests?

Every successful periodical, whether literary, political or scientific reflects its editor's taste and outlook: it is his/her creation by selection and encouragement. Professor Shepherd's creation is a towering achievement. It has impressed his psychiatric outlook on thought, research and academic practice internationally for 20 years. In England, 21 used to be the age of full adulthood. In its young maturity may his journal go from strength to strength.

Formerly Reader in Biological Psychiatry,

John CRAmmer Institute of Psychiatry, London SE5

\section{Medical Aspects of Torture. \\ Danish Medical Bulletin, 37 \\ Supplement No 1, January 1990. pp. 1-88.}

Organised state violence including torture constitutes one of the largest preventable causes of physical and psychological morbidity in the modern world. Amnesty International estimates that about one in three world governments have used torture systematically in the 1980s. Millions have been killed and many more have had to leave their countries in search of refuge.

The Danish Medical Group of Amnesty International, later the Rehabilitation and Research Centre for Torture Victims (RCT), has had an important influence in the world medical response to this issue. Coming from an Amnesty back- ground, the group has led in human rights work. It is disappointing, however, that despite this promising beginning its contribution to the development of psychological and psychosomatic understandings in survivors of torture has not been greater.

This supplement to the Danish Medical Bulletin is devoted to an English language presentation of the results of investigation of 200 torture survivors seen between 1975 and 1982. Some of these results have already been published elsewhere. Most of the sections are detailed descriptions of different physical injuries resulting from torture. Psychological symptoms reported at the time of torture and at subsequent examination are dealt with more briefly. They were common with about two-thirds having long lasting psychological sequelae, chiefly sleep disturbance, irritability, anxiety and depression. Later sections include discussions of the participation of doctors in torture and the role of the medical profession in the prevention of torture.

It is vitally important that doctors and other health professionals are informed about the horrors of organised state violence including torture. It is, after all, inconceivable that torture could take place in any community without the knowledge of health professionals. For those of us in countries of safety and freedom, it is important not only to be able to help the survivors of torture seeking asylum, but also to support the work of colleagues working in great personal danger elsewhere. Any publication which raises awareness of the subject should be welcomed. However, this long article leaves me with a sense of disappointment, a wish that with this large body of data, new insights could have been developed and new interests awakened. The journal will certainly be of relevance as a valuable reference for those who work in the field, but is unlikely to attract a wide readership elsewhere.

STUART TURNER

Senior Clinical Lecturer in Psychiatry,

University College and

Middlesex School of Medicine,

London WIN 8AA 